\title{
Factors Influencing Motivation to Transfer Training: An Empirical Study of a Government Sector Training Program in Sri Lanka
}

\author{
G.T. Madagamage, B.N.F. Warnakulasooriya ${ }^{1}$, and H.V.A. Wickramasuriya ${ }^{2}$ \\ Department of Human Resource Management \\ University of Sri Jayewardenepura \\ Sri Lanka
}

\begin{abstract}
Research related to factors affecting transfer of training in the government sector in Sri Lanka is extremely limited. Hence, this article examines the impact of two trainee characteristics (self efficacy and career commitment) and four work environmental factors (supervisory support, opportunity to perform, awareness of strategic linkages and accountability) on motivation to transfer. Data were collected from 152 officers of the Sri Lanka Administrative Service who participated in a capacity building training program. The Structural Equation Modelling technique was used to test the hypotheses derived from the extensive literature survey. The findings revealed that trainees' self efficacy has a significant impact on the motivation to transfer. Contrary to expectation, the other constructs did not significantly influence the motivation to transfer. The implications of the results and limitations of the study are also noted, along with suggestions.
\end{abstract}

Keywords: Motivation to transfer, training, trainee characteristics, work environmental factors

\section{INTRODUCTION}

Especially in the past two decades human resource management practices are considered as a key business advantage in the face of an increasingly global, competitive and turbulent environment. Among the human resource management strategies, training plays an important role in equipping employees to acquire and update needed competencies in today's organizations. Therefore, both private and public sector organizations spend considerable amounts of money on employee training. The employees acquire new competencies through training; such learning does not always have a payoff in improved work performance (Kontoghiorghes, 2002). Therefore, transfer of training is an important issue addressed by many Human Resource Development (HRD) scholars and professionals in the past and present. Thus, they attempt to understand the training transfer process, the factors that hinder it or facilitate it and the strategies that will enhance the transfer of training from the point of view of trainees, trainers and managers. Transfer of training is described in the literature as the degree to which trainees apply the competencies gained in training to their workplaces (Burke and Hutchins, 2007).

HRD scholars and practitioners have presented models to explain the training transfer process (e.g. Holton, 1996; Kontoghiorghes, 2002), while many scholars identify the factors that can impede or facilitate motivation to learn, motivation to transfer and training

\footnotetext{
${ }^{1}$ Department of Marketing Management, University of Sri Jayewardenepura, Nugegoda, Sri Lanka.

${ }^{2}$ Department of Agriculture Extension, Post Graduate Institute of Agriculture, University of Peradeniya, Sri Lanka.

*Corresponding author: mggtharanganie@yahoo.com
} 
effectiveness. Some of the commonly cited components of key models on training transfer are learning, motivation to learn, factors influencing motivation to learn, motivation to transfer, and factors influencing motivation to training transfer. Some researchers present training motivation as a key determinant of training effectiveness (Holton, 1996; Kontoghiorghes, 2002) and suggest that creating a sense of optimism and capitalizing on motivational variables in training can enhance transfer of training (Pugh and Bergin, 2006; Burke and Hutchins, 2007). According to the researcher's knowledge there is a dearth of published empirical research in the Sri Lankan context regarding the factors affecting the motivation to transfer training. Moreover, much of the literature on transfer of training is from the perspectives of Western countries (Donavan and Darcy, 2011). Few studies have been conducted from a public sector perspective especially in the Asian context. Therefore, this study attempts to fill the above research gap. More specifically, the objective of this study is to identify the impact of trainee and work environmental characteristics on motivation to transfer training, by studying the capacity building training (CBT) program provided to the Sri Lanka Administrative Service (SLAS) Class III officers.

\section{Motivation to transfer}

Holton (1996) has defined motivation to transfer (MT) as trainees' desire to use the knowledge and skills mastered in the training program in their jobs. People's desire to change their behaviour is explained by scholars using three theories: Expectancy theory, equity theory and theory of planned behaviour. Vroom (1964) and some other scholars have explained expectancy as a belief that a particular act will precede a particular outcome and suggesting that behaviour is followed by desirable outcomes. Equity theory is based on the logic that people want to be treated fairly, and thus an individual chooses a method of inequity reduction at the least cost to him or her. Hence, this theory suggests that if trainees feel that by transfer of training that they can gain equity through pay, promotion or any other kinds of rewards, then they will transfer training (Adams, 1963). Ajzen's (2001) theory of planned behaviour gives a foundation to explain the motivational role in the training transfer process. According to the theory of planned behaviour the intention of a person is a function of attitude, subjective norms and behaviour control and these influence willingness. Motivation to transfer has been found to be influenced by individual characteristics and work environmental characteristics (Burke and Hutchins, 2007).

\section{Trainee characteristics}

The role of individual trainees is critical in the training transfer process and understanding the role of trainees will help to find suitable strategies to improve transfer of training. Researchers have identified a significant number of factors under trainee characteristics such as ability, personality, self efficacy, career commitment, work related attitudes, and demographic factors. When determining the scope of the study, this research focused only on two important trainee characteristics, namely self efficacy and career commitment, which had been previously researched and validated in the private sector, but not adequately examined in the public sector.

\section{Self efficacy and motivation to transfer}

According to Paugh and Bergin (2006) self efficacy (SE) is concerned with people's judgment about their capabilities to organize and execute a course of action that is required to attain performance. Further, they have indicated that individuals with high self efficacy are more likely to experience transfer success because the increased cognitive engagement 
associated with high self efficacy should foster the development of a deep level of connected knowledge needed for transfer. Many scholars have found the relationship between self efficacy and motivation to transfer training (Burke and Hutchins, 2007). Moreover, a number of studies indicate that trainees who lack sufficient self efficacy will put less effort to learning and transfer of training since it plays a motivational role, and affects the amount of effort applied to task performance (Tziner et al., 2007). Based on this theoretical and empirical support, the present study hypothesized that self efficacy (H1) is positively relates to motivation to transfer.

\section{Career commitment and motivation to transfer}

Career commitment (CC) refers to the "employee's attitude towards his or her vocation, including a profession" or the "employee's motivation to work in a chosen vocation" (Balu, 1985). In general, career commitment involves development of career goals and willingness to put effort, energy and time to pursuing career goals. Scholars argue that employees with high levels of career commitment may make significant investments in their careers. Career commitment has been studied less frequently (Kontoghiorghes, 2002; Cheng and Hampson, 2008) and mixed findings have been reported on training transfer (Nikandrou et al., 2009). However, it can be hypothesized that career commitment will be a significant determinant of motivation to transfer $(\mathrm{H} 2)$.

\section{Work environmental characteristics and motivation to transfer}

It is widely accepted that trainees' work environment affects motivation to transfer (Burke and Hutchins, 2007; Lim and Morris, 2006). Work environment refers to the current perception of employees, and observable nature of personal relationships that affect the accomplishment of work within a particular organization (Lim and Morris, 2006). Scholars' have identified a significant number of factors in the work environment. The present study selected four factors which may be highly significant in a government executive work environment; supervisory support, opportunity to perform, accountability, and awareness of strategic linkages. Whilst, the impact of supervisory support and opportunity to perform on motivation to learn has been extensively studied, the influence of accountability and awareness of strategic linkages has not been adequately examined (Burke and Hutchins, 2007).

\section{Supervisory support and motivation to transfer}

Supervisory support (SS) refers to the perceived support that a trainee receives from his or her immediate supervisor before and after training (Lim and Johnson, 2002). Supervisory support to the trainees' takes different forms, such as encouraging participation in training, assisting to apply by changing the work environment, providing feedback, and reinforcing positively. Literature reveals that supervisory support influences subordinates' training motivation (Al-Eisa et al., 2009; Chiaburu and Tekleab, 2005) and the level of self efficacy of trainees (Al-Eisa et al., 2009) because it positively impacts trainees' expectancies and instrumentalities (Chiaburu and Tekleab, 2005). Based on the foregoing discussion H3 is formulated as "supervisory support positively influences motivation to transfer".

\section{Opportunity to perform and motivation to transfer}

Opportunity to perform (OP) refers to the extent to which a trainee is provided with or actively obtains work experiences relevant to the tasks for which he or she was trained (Ford 
et al., 1992). The common notion is that if trainees perceived ample opportunities in their working environment he/she will be motivated to learn and be motivated to transfer it to work. Researchers constantly indicate that the lack of opportunities leads to low performance and is a barrier to effective transfer. Seyler et al. (1998) found a significant positive correlation between opportunity to perform and motivation to transfer. Even though there is a dearth of empirical research findings on opportunity to perform and motivation to transfer in public sector organizations, the fourth hypothesis (H4) was formulated based on the above discussion as "opportunity to perform has a positive impact on motivation to transfer".

\section{Awareness of strategic linkages and motivation to learn}

Awareness of strategic linkages (STL) refers to the trainees' perception of the extent to which the training program is aligned with the strategic goals of the organization. In general, trainees who perceive that strategies and the organization or departmental objectives are linked to the training are more likely to be motivated to learn and to transfer learning to the job. Burke and Hutchins (2007) mention the minimum empirical research done on the relationship between awareness of the strategy and training transfer process. As a basic requirement of new public management practices, strategic planning is essential for government sector organizations. On this premise, it is necessary to examine the trainees' level of awareness of the strategic directions of the respective institutions and their impact on motivation to transfer. Therefore, it is hypothesized that 'awareness of strategic linkage positively relates to motivation to transfer' (H5).

\section{Accountability and motivation to transfer}

Accountability (ACC) refers to the degree to which the organization, culture, and/or management expect trainees to use knowledge and skills gained through training on the job and hold them responsible for doing so (Kontoghiorghes, 2002). Burke and Saks (2009) argue that training transfer research and practice have much to gain by focusing more on accountability of training as a key factor for improving training transfer. As Schlenker (1997) states, if a trainee is viewed as accountable for certain behaviours or performance as a psychological adhesive, it would connect to his/her actions and enhance that feeling as an obligation to fulfil it. In general, if trainees perceived that the organization expects trainees to be accountable to apply new competencies after training, they will be motivated to transfer training. Accordingly, the sixth hypothesis is formulated as; 'accountability has a positive impact on motivation to transfer' (H6).

The relationship of the constructs identified, and the relevant hypotheses, are shown in the model used for the study as given in Fig. 1. 


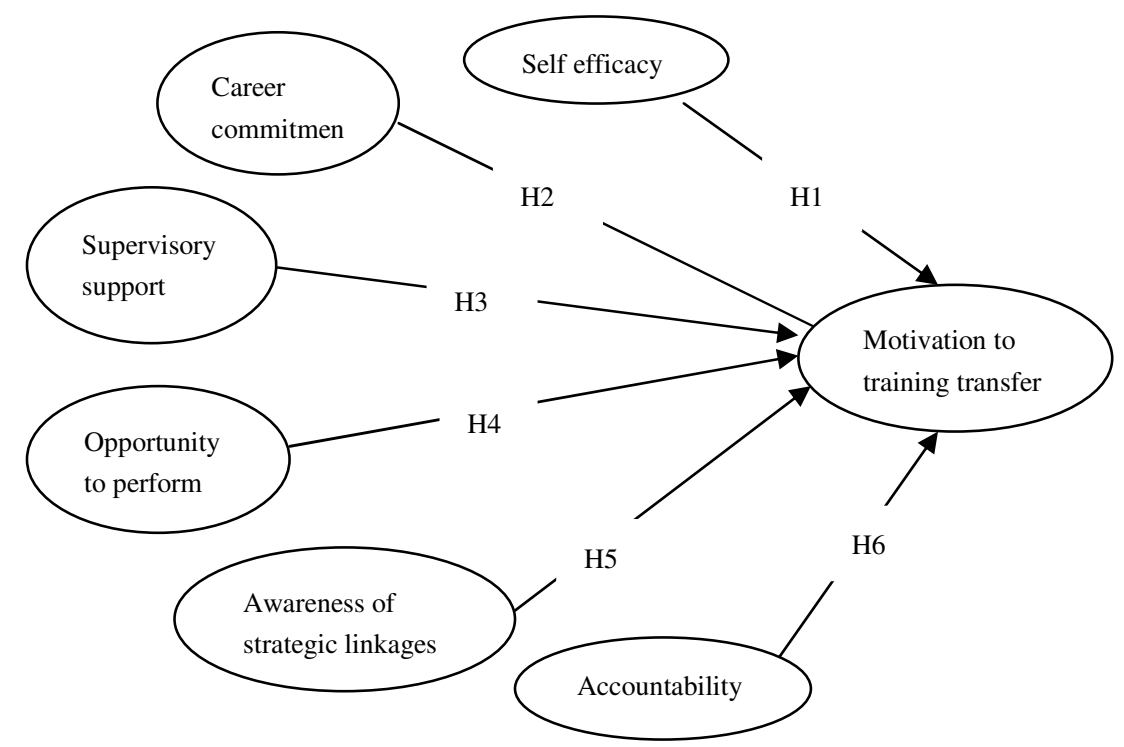

Fig. 1. Proposed model for the study

\section{METHODOLOGY AND RESULTS}

The sample consisted of all SLAS Class III officers (i.e. 236) who participated in the Capacity Building Training (CBT) program, conducted by the Sri Lanka Institute of Development Administration during the years 2011 and 2012. This cohort was considered as a sample of all CBT trainees. From the sample, 152 officers responded to the questionnaire. The program, duration, which was around 29 working days, included approximately 63 hours of sessions. The sample profile included an equal number of male and female respondents, $82 \%$ were married, $96 \%$ were between 31 and 40 years old, $48 \%$ had completed postgraduate degrees, $20 \%$ held postgraduate diplomas and the rest possessed a bachelor's degree, $2 \%$ had more than 10 years experience in the SLAS, $78 \%$ had 6 to 10 years experience, while $20 \%$ had less than 5 years experience.

\section{Self efficacy}

This construct was measured by six indicators, out of which three were directly derived from Machin and Fogarty (1997) and the rest were developed by the authors based on the previous literature. A sample item is "I am confident that I can perform satisfactorily during the training".

\section{Career commitment}

Six items developed by Balu in 1985, and further validated by Carson and Bedeian (1994) were employed to tap career commitment. A sample item is "This line of work/ career field has a great deal of personal meaning to me". 


\section{Supervisory support}

This construct was captured through six items out of which, four items were slightly modified versions of the original sources of Ai-Eisa et al. (2009), Xiao (1996), Chiaburu and Tekalab (2005). A sample items is "My supervisor encourages me to attend this training program".

\section{Opportunity to use}

Four items based on the study of Ford et al. (1992) were developed to capture the domain of Opportunity to Use. A sample item is ". I will have an opportunity to perform the skills that I have learned in the training".

\section{Awareness of strategic linkages}

This construct was measured using four items developed by Montesino (2002) with a few modifications. A sample item is "I am aware of the mission, strategic goals and strategic direction of the organization".

\section{Accountability}

Five items based on the work of Burke and Saks (2009) were employed to measure the accountability construct. A sample item is" I am aware of the organization's expectations from this training program".

\section{Motivation to transfer}

This construct was measured using six items developed by Machin and Forgarty (1997). A sample item is "I intend to use the knowledge and skills acquired from this program when back on the job".

Perceptual evaluation of the respondents on the above items was taken by using a five point Likert scale $(1=$ strongly disagree; $2=$ disagree; $3=$ neither agree nor disagree; $4=$ agree; $5=$ strongly agree).

\section{Validation of measurement properties}

A pilot study with a sample of 46 elements was carried out to validate and refine the questionnaire before it was administered in the main survey. Measurement properties such as reliability, convergent and discriminant validity were examined. The results of the respective tests are given in Table 1. 
Table 1. Summary results of the pilot test

\begin{tabular}{lcccccc}
\hline Construct & $\begin{array}{l}\text { Original } \\
\text { items }\end{array}$ & $\begin{array}{c}\text { Deleted } \\
\text { Items }\end{array}$ & AVE & $\begin{array}{l}\text { Cronbatch's } \\
\text { Alpha }\end{array}$ & KMO & $\begin{array}{l}\text { Composite } \\
\text { Reliability }\end{array}$ \\
\hline $\begin{array}{l}\text { Self Efficacy } \\
\text { (SE) }\end{array}$ & 6 & 3 & 0.652 & 0.731 & 0.628 & 0.848 \\
$\begin{array}{l}\text { Career } \\
\text { Commitment } \\
\text { (CC) }\end{array}$ & 6 & 3 & 0.639 & 0.711 & 0.638 & 0.839 \\
$\begin{array}{l}\text { Supervisory } \\
\text { Support (SS) }\end{array}$ & 6 & 0 & 0.723 & 0.919 & 0.849 & 0.939 \\
$\begin{array}{l}\text { Opportunity to } \\
\begin{array}{l}\text { Perform (OP) } \\
\text { Awareness of }\end{array}\end{array}$ & 4 & 1 & 0.547 & 0.711 & 0.611 & 0.881 \\
$\begin{array}{l}\text { Strategic Linkage } \\
\text { (STL) }\end{array}$ & 4 & 0 & 0.643 & 0.809 & 0.633 & 0.878 \\
$\begin{array}{l}\text { Accountability } \\
\text { (ACC) }\end{array}$ & 5 & 1 & 0.619 & 0.793 & 0.716 & 0.864 \\
$\begin{array}{l}\text { Motivation to } \\
\text { Transfer (MT) }\end{array}$ & 6 & 2 & 0.649 & 0.811 & 0.798 & 0.881 \\
\hline
\end{tabular}

The data in Table 1 clearly shows that all the constructs exceed the standard value of Cronbach's alpha of 0.7 ensuring internal consistency among the items. Factor analysis was performed to examine whether the items converged on the respective constructs. Originally, thirty seven items were developed for capturing the constructs of the study and ten items that were poorly loaded were deleted based on the results of the exploratory factor analysis. The items used in the final questionnaire are given in the Appendix. The Kaiser-Meyer- Olkin (KMO) measure of sampling adequacy was used to examine the appropriateness of the factor analysis. All the KMO values were found to be over 0.5, indicating sampling adequacy (Malhotra, 1993). Bartlett's test of sphericity was performed to examine whether the indicators of the respective constructs are correlated in the population (Hair et al., 1998). All the Chi square values of the Bartlett's test are significant at alpha $=0.05$ level, suggesting that each indicator is highly correlated with the other indicators (Malhotra, 1993). In addition, the average variance extracted (AVE), and the composite reliability for each construct was examined. All AVE values exceed the standard value of 0.5 while all composite reliability values exceed the standard value of 0.7 . The results of these tests ensure convergent validity.

\section{Statistical method}

Structural equation modelling (SEM) was used to test the hypotheses of the study because recently SEM has been extensively used for model testing and it is an extension of multiple regression analysis and factor analysis (Hair et al., 1998). Even though SEM is more suitable for large samples Iacobucci (2010) has mentioned that if the variables are reliable, and the model not overly complex, a sample size of 150 will usually be sufficient for a convergent and proper solution. SEM includes two steps: validating the measurement model by conducting confirmatory factor analysis (CFA) and fitting the structural model (Hair et.al, 1996). 


\section{Measurement models}

The data collected through the refined questionnaire was used for validating the measurement model through confirmatory factor analysis (CFA) using the Amos 21 software package. Commonly used fit indices such as relative chi- square, goodness of fit index (GFI), adjusted goodness of fit index (AGFI), comparative fit index (CFI), Tucker Lewis index (TLI) and root mean square error of approximation (RMSEA) (Hair, et al., 1998) were estimated for validating the measurement model. Results of the final measurement models are recorded in Table 2 .

Table 2. Goodness of fit indices of each measurement model

\begin{tabular}{lcllllr}
\hline Variable & Chi square/df & GFI & AGFI & CFI & TLI & RMSEA \\
\hline SE & 1.01 & 0.998 & 0.986 & 0.990 & 0.999 & 0.001 \\
CC & 1.02 & 0.999 & 0.994 & 0.990 & 0.999 & 0.001 \\
SS & 1.915 & 0.959 & 0.913 & 0.980 & 0.970 & 0.078 \\
OP & 1.1 & 0.995 & 0.971 & 0.999 & 0.996 & 0.026 \\
STL & 1.223 & 0.992 & 0.960 & 0.997 & 0.992 & 0.038 \\
ACC & 1.232 & 0.995 & 0.968 & 0.998 & 0.994 & 0.039 \\
MT & 1.919 & 0.981 & 0.938 & 0.985 & 0.969 & 0.078 \\
Accepted & 1 to 3 & $\geq 0.9$ & $\geq 0.9$ & $\geq 0.9$ & $\geq 0.9$ & $\leq 0.08$ \\
Standard & & & & & & \\
\hline
\end{tabular}

Goodness of fit indices in Table 2 reveal that all fit indices exceed the acceptable limits, suggesting a satisfactory overall fit of the measurement models. Standard estimates, standard errors and critical ratios were examined for each measurement model, and the results revealed that standard estimates of all the items are above 0.5 , indicating good convergent validity (Hair et.al., 1996). Further, all items were statistically significant with critical ratio values exceeding 1.96, suggesting the unidimensionality of the measurement models.

\section{Structural model}

Measurement models on each construct were used to develop a structural model which examines the impact of six exogenous variables: self efficacy, career commitment, supervisory support, opportunity to perform, awareness of strategic linkages and accountability on an endogenous variable, motivation to transfer. Fit indices of the initial structural model were below the threshold values. Thus, it was reestimated to improve the model fit by removing some items as suggested by modification indices. Fit indices of the intial and reetimated model are recorded in Table 3.

Table 3 Fit indicies of the initial and reestimated model

\begin{tabular}{llllllll}
\hline & Chi square/df & GFI & AGFI & CFI & TLI & RMSEA & R $^{2}$ \\
\hline Initial Model & 1.713 & 0.812 & 0.766 & 0.841 & 0.818 & 0.069 & 0.42 \\
Re-estimated & 1.229 & 0.900 & 0.859 & 0.966 & 0.957 & 0.039 & 0.35 \\
Model & & & & & & & \\
\hline
\end{tabular}

AGFI $\geq 0.85$ marginal fit (Hair et.al., 1998)

$\mathrm{R}^{2}$ of the reestimated model is 0.35 suggesting that the model explains $35 \%$ of the variance on motivation to transfer. Estimates, critical ratios and standard errors of the structural paths 
of the model are recorded in Table 4 . The results indicate that self efficacy has a positive impact on motivation to transfer (St. estimate $=0.40$, Critical ratio $=2.75, \mathrm{p}<0.05$ ) supporting $\mathrm{H} 1$ of the study. Hypothesis 2 stated that career commitment is a significant determinant of motivation to transfer. The results did not support $\mathrm{H} 2$ (St. estimate $=0.004$, Critical ratio $=0.029 \mathrm{p}>0.05)$ thus career commitment does not seems to have an impact on motivation to tranfer. Similarly, emperical evidences of this study do not support H3, H4, H5 and H6.

Table 4. Estimates, critical ratios and regression weights

\begin{tabular}{|c|c|c|c|c|c|c|}
\hline & & Un St.Est. & S.E. & C.R. & $\mathrm{P}$ & St. Est. \\
\hline MT & $<\mathrm{SE}$ & .461 & .168 & 2.750 & .006 & .400 \\
\hline MT & $<\mathrm{CC}$ & .003 & .102 & .029 & .977 & .004 \\
\hline MT & $<\mathrm{SS}$ & .077 & .063 & 1.226 & .220 & .127 \\
\hline MT & $<\mathrm{OP}$ & .095 & .084 & 1.13 & .258 & .122 \\
\hline MT & $<$ STL & .176 & .095 & 1.851 & .064 & .228 \\
\hline MT & $<\mathrm{ACC}$ & .031 & 0.57 & .538 & .591 & .045 \\
\hline
\end{tabular}

\section{DISCUSSION}

The findings of this study suggest that self efficacy is an important determinant of motivation to transfer. This result confirms the findings of Ai-Eisa et.al (2009), Chiaburu et.al. (2010) and Ford et.al. (1992).

Results of the second hypothesis testing fail to support the work of previous scholars, Cheng and Ho (2001) and Nikandrou et al. (2009) who studied the sample from the private sector organizations and claimed that career commitment has an influence on motivation to transfer. This contradiction might be due to poor HRM practices in the government sector, such as low attention paid by government organizations and individuals to personal and career development plans, employees' perceptions of a mismatch between promotion and performance, and ineffective performance appraisal systems. In brief, motivation to transfer does not occur due to career commitment. However, this result is in line with the findings of Madagamage (2013).

Hypothesis three was not supported by the data suggesting that supervisory support doesn't significantly affect motivation to transfer training. This is contradictory to the findings of AlEisa et al. (2008), Liebermann and Hoffmann (2008) and Seyler et al. (1998). Velada et al. (2007) found no statistical significant relationship between supervisory support and transfer of training. Nijman et al. (2006) indicated that supervisory support has a direct negative effect on motivation to transfer. The possible explanation of this may be the management style of the superiors, who may feel that encouragement or guidance is not required for executives.

The present study reveals that opportunity to perform is not a predictor of motivation to transfer, which is not in line with the findings some of the scholars (Lim and Johnson, 2002; Seylar et al., 1998). The reason for H4 not being significant may be the more theoretical orientation of the program and the fact that many of the skills the trainees acquired being not related to the present job tasks as mentioned by participants in the interviews. The findings on $\mathrm{H} 5$ and $\mathrm{H} 6$ suggest that awareness of strategic linkages and accountability do not 
significantly influence motivation to transfer. The reason for not being accountable for training transfer may be the trainees' perception that they do not have any legal binding or mechanism to evaluate the progress of training transfer.

\section{THEORETICAL AND PRACTICAL IMPLICATIONS}

The findings have both managerial and theoretical implications. Firstly, two work environmental factors (i.e. awareness of strategic linkages and accountability), not extensively researched, were examined in this study and found to be not significant. Secondly, this study empirically validates previous finding, self efficacy is significant predictor on motivation to transfer training and gives new insights for further examination. Thirdly, many previous studies on transfer of training have been conducted in Western countries and in private sector organizations (Machin and Fogarty, 1997; Velada et al., 2007). Thus, the findings of the present study help to understand factors that influence motivation to transfer in a different context, especially to one important segment in the government sector.

This study offers practical possibilities on how to optimize motivation to transfer, which leads to better training transfer. Accordingly, HRD managers should design their training interventions in a manner that increases self efficacy, because it enhances motivation to transfer. For example, the need to find strategies to enhance self efficacy such as encouragement, linking training to promotion and increments and enhancing learning. Furthermore, HRD managers need to examine the reason for career commitment not influencing motivation to transfer, and take necessary remedial strategies accordingly to ensure returns on investment on management development. At present no mechanism (e.g. post training reports, interviews, and certain prescribed standards) operates in some public sector organizations to hold trainees effectively accountable for after training outcomes. If mechanisms to hold trainees accountable for training transfer are introduced, future studies might show an influence of accountability to motivation to transfer. Similarly providing trainings which are aligned with the strategic directions of the organization and giving awareness about the linkages between training and strategic plans of the organization may enhance motivation to transfer.

\section{LIMITATIONS AND DIRECTIONS FOR FUTURE RESEARCH}

Several limitations of this study should be noted. Firstly, all the variables examined were measured by self reported data and data was collected through a cross sectional design. Some scholars have mentioned that gathering data from multiple sources may be more accurate and that measuring attitudes through a longitudinal design might be more appropriate. Secondly, the study enumerated a sample of only 152 elements from a limited cohort. Hence, with respect to generalizability, using a more diverse and larger sample could enable extending the results more confidently. Thirdly, the theoretical and empirical effort of this study is limited to examine only the influence of two trainee characteristics and four work environmental factors on motivation to learn. Many other variables related to trainee characteristics, work environment and training design were not considered in the proposed model due to the scope of the study. Future research should be conducted to address these gaps, taking the limitations mentioned herein into account. Future research could also take into account the influence of organizational culture and the public sector work ethos on the motivation to transfer. 


\section{CONCLUSION}

The objective of this study was to gain a better understanding of the impact of trainee characteristics and work environmental factors on motivation to transfer training. This study concludes that self efficacy has a strong influence on motivation to transfer training in Class III SLAS officers who followed the Capacity Building Training program provided by the Sri Lanka Administrative Service. However, the constructs career commitment, supervisory support, opportunity to perform, awareness of strategic linkages, and accountability did not have a statistically significant influence on motivation to transfer training.

\section{REFERENCES}

Adams, J.S. (1963).Towards an understanding of inequity, Journal of Abnormal and Normal Psychology, 67, 422 - 463.

Ajzen, I. (2001). Nature and Operations of attitudes, Annual Review of Psychology, 60, 451 $-474$.

Al-Eisa, A.S., Furayyan., M.A. and Alhemoud, A.M. (2009). An empirical examination of the effects of self - efficacy, supervisor support and motivation to learn on transfer intension, Management Decision, 47(8), 1221 - 1242.

Balu, G.J. (1985). The measurement and prediction of career commitment, Journal of Occupational Psychology, 58, 277 - 288.

Burke, L.A. and Hutchins, H.M. (2007). Training transfer: An integrative literature review, Human Resource Development Review, 6(3), 142 - 163.

Burke, L.A. and Saks, A.M. (2009). Accountability in Training Transfer: Adapting Schlenker's Model of Responsibility to a Persistent but solvable Problem, Human Resource Development Review, 8(3), 382 - 402.

Carson, K.D. and Bedian, A. (1994). Career Commitment: Construction of a Measure and Examination of it Psychometric Properties, Journal of Vocational Behavior, 44, 237 - 262.

Cheng, E.W.L. and Hampson, I. (2008).Transfer of training: A Review and new insight", International Journal of Management Review, 10(4), 327 - 341.

Chiabura, D.S., Dam, K.V. and Hutchins, H.M. (2010). Social support in the workplace and training transfer: A longitudinal analysis, International Journal of Selection and assessment, $18(2), 188-203$.

Chiaburu, D.C. and Tekleab, A.G. (2005). Individual and contextual influences on multiple dimensions of training effectiveness, Journal of European Industrial training, 29(80), 604 626.

Donovan, P. and Darcy, D.P. (2011). Learning Transfer: the views of practitioners in Ireland, International Journal of Training and Development, 15(2), 121 - 136. 
Ford, J.K., Quinones, M.A., Sego,D.J. and Sorra, J.S. (1992). Factors affecting opportunity to perform trained tasks on the job, Personnel Psychology, 45(3), 511 - 527.

Hair, J.F. Anderson, R.E., Tatham, R.L. and Black, W.C. (1998). Multivariate Data Analysis, $\left(\right.$ Ed. $\left.5^{\text {th }}\right)$, Prentice- Hall International Inc.

Holton, E.F.III (1996). The flawed four level evaluation model, Human Resource Development Quarterly, 7, 5 - 21.

Iacobucci, D. (2010). Structural Equation Modeling: Fit indices, Sample Size and Advanced Topics, Journal of Consumer Psychology, 90 - 98.

Kontoghiorghes, C. (2002), Predicting motivation to learn and motivation to transfer learning back to the job in a service organization: A new systematic model for training effectiveness, Performance Improvement Quarterly, 15(3), 114 - 129.

Liebermann, S. and Hoffmann, S. (2008). The impact of practical relevance on training transfer: evidence from service quality training program for German bank clerks, International Journal of training and Development, 12(2), 74 - 86.

Lim, D. and Johnson, S. (2002). Trainee Perception of factors that influence learning transfer, International Journal of Training and Development, 1(6), 36 - 48.

Lim, D.H. and Morris, M.L. (2006). Influence of Trainee Characteristics, Instructional Satisfaction, Organizational Climate on Perceived Learning and Transfer of Training, Human Resource Development Quarterly, 17(1), 85-104.

Machin, M.A. and Fogarty, G.J. (1997). The effects of self- efficacy, motivation to transfer and situational constraints on transfer intention and transfer of training, Performance Improvement Quarterly, 10(2), 98 - 115.

Madagamage, G.T. (2013). The Influence of Career Commitment on Motivation to Learn and Motivation to Transfer, Asian Journal of Business Administration, 1(3), 78 - 86.

Malhotra, N.K (1993) Marketing Research an Applied Orientation, Prentice Hall, Englewood Cliffs, New Jersey.

Montesino, M.U. (2002). Strategic Alignment of Training, Transfer- Enhancing Behaviors and Training Usage: A post Training Study, Human Resource Development Quarterly, 12(1), 89-108.

Nijman, D.J.M., Nijho.f., W.J, Woggnum., A.A.M. and Veldkamp, B.P. (2006). Exploring differential effects of supervisor support on transfer of training, Journal of European Industrial Training, 30(7), 529 - 549.

Nikandrou, I , Brinia, V. and Bereri, E (2009). Trainee perceptions of training transfer: an empirical analysis, Journal of European Industrial Training, 33(1), 255 - 270.

Paugh, K.J. and Bergin, D.A. (2006). Motivational Influences on Transfer, Educational Psychologist, 4(3), 147 - 160. 
Schlenker, B.R. (1997). Personal responsibility: Application of the triangle model, Research in Organizational Behavior, 19, 241 - 301.

Seyler, D.L., Holton, E.F III, Bates, R.A., Burnett, M.F. and Carvalho, M.A. (1998). Factors affecting motivation to transfer training, International Journal of Training and Development $2(1), 2-15$.

Tziner, A ., Fisher, M., Senior, T. and Weisberg, J. (2007). Effects of Trainee Characteristics on Training Effectiveness, International Journal of Selection and Assessment, 15(2), 167174.

Velada, R., Caetano, A., Michel, J.W., Lyons, B.D. and Kavanagh, M.J. (2007). The effects of training design, individual characteristics and work environment on transfer of training, International Journal of Training and Development, 11(4), 282 - 294.

Vroom, V. (1964). Work and Motivation, New York, Wiley.

Xiao, J. (1996). The Relationship between Organizational Factors and the Transfer of Training in the Electronic Industry in Shenzhen, China, Human Resource Development Quarterly, 7(1), 55 - 73.

\section{Appendix}




\title{
List of items in the questionnaire after the pilot survey
}

\author{
Self efficacy \\ 1. I am confident that I am able to effectively use the skills learned in the course \\ 2. I am confident that I am able to develop expertise in the skills learned from the course \\ 3. I am confident that I am able to overcome any obstacles I face when applying the new knowledge or skills \\ learned in the course \\ Career commitment \\ 4. This line of work/ career field has a great deal of personal meaning to me \\ 5. I clearly identify my chosen line of work/career field \\ 6. I have created a plan for my development in this line of work/ career field \\ Supervisory support \\ 7. My supervisor encourages me to attend this training program \\ 8. My supervisor will provide resources needed to apply new competencies acquired from the training \\ 9. My supervisor will provide the time needed to practice the skills learned in training \\ 10. My supervisor provides assistance when I have problems in applying the new competencies \\ 11. My supervisor gives recognition and credit to those who apply new competencies on their job. \\ 12. My supervisor will informs me how well I have accomplished tasks using new competencies \\ Opportunity to perform \\ 13. I have the opportunity to apply the skills that I have learned in the training \\ 14. I will have the opportunity to apply the trained skills repeatedly in the organization \\ 15. I will have the opportunity to do minor changes in the organization using the skills I have learned from the \\ training \\ Awareness of strategic linkages \\ 16. I am aware of the mission, strategic goals and strategic direction of the organization. \\ 17. I am aware of the strategic plan (cooperate plan) of my department. \\ 18. This training program helps me to achieve the set departmental goals \\ 19. I am committed to learn on this training program because these competences help to achieve the set \\ departmental goals \\ Accountability \\ 20. I am aware of the organizational expectations of the competencies should acquire from this training \\ program \\ 21. My superior has discussed what I should acquire from this training program \\ 22. I know that I have to provide a detailed presentation/ report on the competencies acquired in this training \\ 23. Supervisor and I set specific goals for applying the competencies acquired through the training and evaluate \\ them at the performance appraisal. \\ Motivation to transfer \\ 24. I intend to use the knowledge and skills acquired from this program when I get back on the job \\ 25. I will set the specific goals for maintaining the skills that I have learned. \\ 26. I will examine the potential barriers to using the skills that I have learned
}

27. I will discuss with the peers the ways to use the skills that I have learned 